\title{
The Parent Interaction Assessment, in Children with Autism, to Help the Short Therapeutic Counseling
}

\author{
Ivanova Veronika \\ Medical University of Varna, Varna, Bulgaria \\ Email: veronika_ivanovi@abv.bg
}

How to cite this paper: Veronika, I. (2021). The Parent Interaction Assessment, in Children with Autism, to Help the Short Therapeutic Counseling. Psychology, 12, 1085-1088.

https://doi.org/10.4236/psych.2021.127065

Received: June 23, 2021

Accepted: July 16, 2021

Published: July 19, 2021

Copyright (C) 2021 by author(s) and Scientific Research Publishing Inc. This work is licensed under the Creative Commons Attribution International License (CC BY 4.0).

http://creativecommons.org/licenses/by/4.0/

\begin{abstract}
The purpose of this study is to propose a method of complementary data unification obtained through both direct observation and themes in parents' narratives about autism. Sixty children with autism were studied in indirect therapeutic consultation with parents. Methods used: review of a direct parent-child interaction observation, content analysis, and interpretive phenomenological analysis of the main themes that emerged in the process of interaction with mothers and fathers of autistic children. The independent variable are the themes that we output with a contrarian analysis are the behavioural aspects of the interaction. The results identified the main subjective themes for parents-aggression, rejection, future, isolation, hopelessness. In the control sheets stand out not calling the child by name, talking sharply to the child, hiding for him and on him, low emotional expression to the child and difficulties with the level of affection and symbiosis. In summary, we can say that the simultaneous reporting of objective facts from direct observation, combined with giving space and understanding the unconscious fantasies of the parent shared in the speech, is a method of improving the skills of brief therapeutic counselling techniques in the interaction of parents and children with autism.
\end{abstract}

\section{Keywords}

Autism, Parent

\section{Introduction}

The rationale for conducting this study lies in the idea that the early mother-baby relationship is important and crucial to the formation of the subject. This study examined the unconscious side of these relationships, which is rarely 
addressed in the literature pertaining to parenting and autism research. Although the literature on parent-child interactions in young children with autism has examined dyadic style, synchrony, and sustained engagement, the study of the unconscious part of the relationship, parental fantasy and hidden anxiety, has not been targeted (Freeman, 2013; Frey, 2011). Numerous publications (Lefort, 1995; Lebovici, 2006, Basso, 2013; Frith, 2003; Laznik, 1997; Yankelevech, 1988; Winnicott, 1971) show that joint interpretive therapy (mother-child) is a major clinical and theoretical interest. In the mother-child study, when an autistic child is not speaking, the mother's behaviour is strongly influenced by her fantasy world (Tendlarz, 1996). Direct observation and therapeutic consultation are necessary to improve parent-child interaction. Several authors emphasise the importance of the space created by the therapist, which allows listening to the mother's narrative to also therapeutically guide the relationship with the child. The process of evaluating the interaction, besides releasing healing tendencies (Melzer, 1975). According to (Mahler, 1952), in the parent relationship-autistic child, there is a failure in the symbiotic phase, it raises its keys.

In the meta-analysis of 17 studies from six countries (USA, UK, Australia, Canada, Thailand and China) that recruited 919 children with ASD (Oono, 2013), there was no statistical evidence of gains from parent-mediated approaches in most of the primary outcomes assessed, the evidence for positive changes in patterns of parent-child interaction was strong and statistically significant (Oono, 2013). Oono's review, which finds some evidence for the effectiveness of parent-mediated interventions, particularly for proximal indicators within parent-child interactions, highlights the need to focus attention on service models for early intervention that allow parents to skillfully contribute to the treatment of their child with autism. In another systematic review, $\mathrm{McCo}-$ nachie (2007) found very few studies that had adequate research designs from which to draw conclusions about the effectiveness of parent-implemented early interventions.

\section{Materials and Methods}

The study sample consisted of 60 children diagnosed with autism spectrum disorder (ASD). The study design is cross-sectional. Description of participants: 60 children on the autism spectrum (inclusion criteria are psychiatric diagnosis and score of CARS 2) with parents and aged between 2 and 17 years participated in this study $(M=8.87$ years; $S D=2.17)$. Of these $(40 \%$ girls $)$, the children with CARS 2 were examined with varying degrees of disability.

For the study of parent-child relationship, a checklist and a consultation with the parents and with the child by a clinical psychologist, psychotherapist is used.

1) Checklist a) talks to the child and not at (for) him; b) addresses the child by name; c) emotional expression of the parent in front of the child; d) attempts to suggest what the child wants to say; e) the parent is able to engage in the child's play; f) the parent is tolerant of the child's closedness and lack of communication; g) holds the ability to talk to the child and gives space to respond, even 


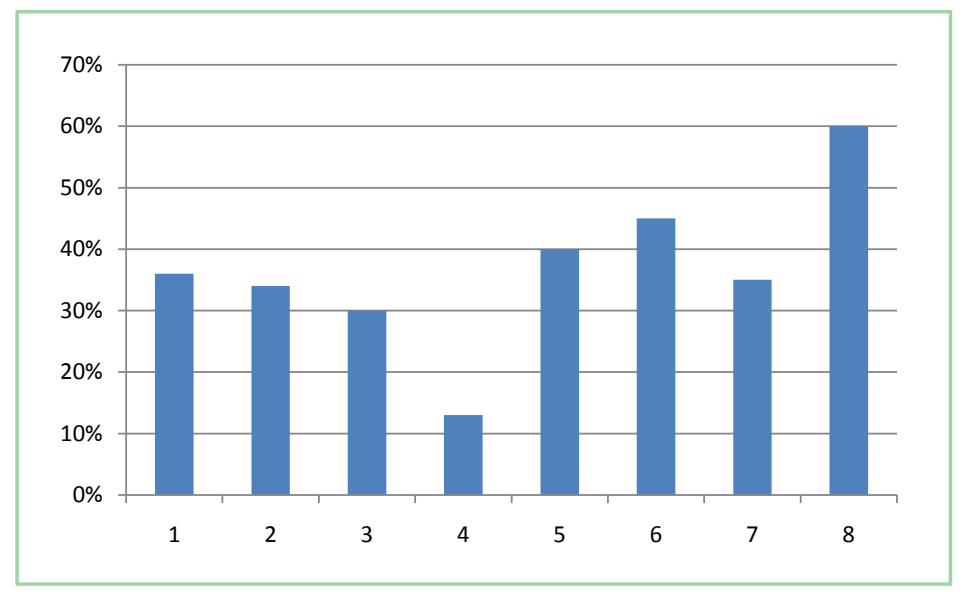

Figure 1. Grafik 1-chek list results.

with a nonverbal child; h) touching. 2) An interpretative phenomenological analysis of therapeutic sessions conducted with parents of autistic children.

\section{Results}

Of the results presented, the largest percentage has touches $(60 \%)$, while the other tick sheets do not exceed 50\%. The most difficult thing for the parents is to suggest to the child what he wants to say (13\%), they talk rather than do it. They often talk about him or with him (36\%), but they find it difficult to talk to a non-verbal child, to address him by name (34\%), not always to engage in the child's play (40\%) and to give space to the response (35\%). Low is the emotional expression, only $35 \%$ of parents (See Figure 1).

In their subjective parts, many fears appear, some of them can hardly realize it and fear that the child will hurt them or will hurt them, the fear of aggression makes them helpless and they relax when they understand that the aggression of the autistic child is self-defense. Many feel rejected by their autistic children and in most of them there are fears of the future, death fantasies and that the KCA will do without the child, which should also be processed in therapeutic communication.

\section{Conclusion}

The role of the therapist is to make sense of the child's behavior, i.e., to indirectly show the parents how to do it. In the therapeutic sessions, the issues related to the need to talk to the nonverbal child are discussed. The goal is to get help with "untangling" in addition to the projections the child makes onto him/herself (Laznik, 1997). This, in turn, can only be done in a therapeutic, not didactic-pedagogical, setting when the data obtained from direct observation is merged with the subjective narrative of the parent. If we want to know more about the parental communication with the child, the careful study of the unconscious processes it is important, which indirectly influences the contact between them. Awareness of projections, fantasies, and fears leads to authentic contact with the child, and un- 
like direct approaches that leave parents feeling unable to communicate with their own child, the consultative approach that combines both child behavior and receiving unconscious projections for the parent should be explored in future studies. The review highlights the need for improved research in this area.

\section{Conflicts of Interest}

The author declares no conflicts of interest regarding the publication of this paper.

\section{References}

Basso, M. (2013). Una aproximación psicoanalítica al Autismo. Ed. Letra Viva, Buenos Aires, p. 24.

Freeman, S., \& Kasari, C. (2013). Parent-Child Interactions in Autism: Characteristics of Play. Autism, 17, 147-161. https://doi.org/10.1177/1362361312469269

Frey, J. R., \& Kaiser, A. P. (2011). The Use of Play Expansions to Increase the Diversity and Complexity of Object Play in Young Children with Disabilities. Topics in Early Childhood Special Education, 31, 99-111. https://doi.org/10.1177/0271121410378758

Frith, U. (2003). Autism: Explaining the Enigma. Oxford: Basil Blackwell

Laznik, M. (1997). Hacia el habla. Tres niños autistas en psicoanálisis Nueva Visión. Buenos Aires.

Lebovici, S. (2006). Fantasmic Interaction and Intergenerational Transmission. Infant Mental Health Journal, 9, 10-19.

Lefort (1995). R.Nacimiento del Otro. Paidos. Barcelona.

Mahler, M. (1952). On Child Psychosis and Schizophreniq. Autistic and Symbiotic, Infantile Psychoses. The Psychoanalytic Study of the Child, 7, 286-305. https://doi.org/10.1080/00797308.1952.11823164

McConachie, H., \& Diggle, T. (2007). Parent Implemented Early Intervention for Young Children with Autism Spectrum Disorder: A Systematic Review. Journal of Evaluation in Clinical Practice, 13, 120-129. https://doi.org/10.1111/j.1365-2753.2006.00674.x

Melzer, D. (1975). Explorations in Autism: A Psychoanalytic Study (1975). Perthshire: Clunie Press.

Oono, I. P., Honey, E. J., \& McConachie, H. (2013). Parent-Mediated Early Intervention for Young Children with Autism Spectrum Disorders (ASD). Evidence-Based Child Health, 8, 2380-2479. https://doi.org/10.1002/ebch.1952

Tendlarz, S. (1996). De qué sufren los niños? La psicosis en la infancia; Lugar editorial Buenos Aires, 1996.

Winnicott, D. (1971). Playing and Reality (Penguin). Oxfordshire: Routledge

Yankelevech, H. (1988). Ensayos sobre autismo y psicosis Kliné. Buenos Aires. 